This is a post-print (author's final draft) of a chapter in Marc Leman (Ed.) (1997). Music, Gestalt and Computing. Studies in Cognitive and Systematic Musicology. Springer Verlag: Berlin - Heidelberg. [Original page numbers between square brackets]. Details of the definitive version are available at http://books.google.de/books?id=XAakPALTuoC\&pg=PA453\&hl=nl\&source=gbs_selected_pages\&cad=3\#v=onepage \&q\&f= false

\title{
Gestalt Concepts and Music: Limitations and Possibilities.
}

Mark Reybrouck

University of Leuven, Blijde inkomststraat 21, PO Box 3313, B-3000 Leuven, Belgium

\begin{abstract}
This paper is concerned with possible applications of Gestalt concepts in relation to music. The concepts are examined as to their limitations and possibilities. We propose a reappraisal of some older insights and an enlargement of the Gestalt concepts from a rather intuitive to an operational approach, arguing strongly for using the methodology of interdisciplinary research, and stressing the importance of the cognitive view of elaboration and processing of musical structure by the listener's mind. This involves a shift from structural description to a functional approach, with special emphasis on musical information processing. Furthermore attention is directed to the specificity of music as a temporal and sounding art, stressing the role of memory and imagination, and the tension between actuality and virtuality in the construction of musical Gestalts.
\end{abstract}

\section{Introduction}

[57] Gestalt-theoretical insights belong to the common equipment of psychological research. They strongly influenced learning theories, in stressing the importance of the progressive and meaningful organization of the perceptual field, and are now enjoying a renewed level of interest. To quote Hofstadter: "In any case, it will be good when AI people are finally driven back to looking at the insights of people working in the 1920's, such as Wittgenstein and his 'games', Koehler and Koffka and Wertheimer and their 'gestalts', and Terman and Binet, and their IQ-problems" (Hofstadter, 1986, p. 638). Modern technological means and the refinement of measuring devices and methodologies of research, however, suggest orientations other than the rather intuitive formulations of the early pioneers. The proposal of this paper is to explore this new impetus in outlining a possible enlargement of Gestalt concepts with special attention to the interdisciplinary approach and the role of the subject in the experience of 'his' Gestalts.

\section{Gestalt Theory and Music: Limitations and Possibilities}

The application of gestalt-theoretical concepts to the domain of music is not without risks The intuitive character of their general claims and the highly speculative character of extrapolation of experiences from the visual domain into other fields of experience are waiting for empirical 
[58] support. Much groundwork still has to be done, not only in the empirical domain but also at the conceptual level. It may be interesting therefore to trace some general outlines of the foundation of Gestalt Theory.

\subsection{Philosophical and Biological Foundations}

Gestalt theory (Köhler, 1929; Wertheimer, 1958; Koffka, 1935) was originally a psychological theory, that widened its claims to general philosophical conceptions about biological and physical facts. The theory therefore partly fits in with the organismic conception of von Bertalanffy (1949), a view that transcends the mechanistic and vitalistic views of science by stressing the idea of totality. The starting points of this conception of the world are three fundamental principles of modern biology: the principle of totality (not only the parts and the processes, but also their relationships), the organic principle (the organization leans upon the hierarchical order of the organism), and the principle of dynamics (living beings not merely exist, but they 'occur'). The organismic conception, therefore, is opposed to the three traditional paradigms of scientific methodology: the analytic-summative conception that analyses firts, to put the parts together thereafter, the machine-theoretical conception that reduces the order of living processes to the conditions that are inherent in the structure of the organisms, and the reaction-theoretical conception of the organism as an automaton, that reacts in a pre-established way on stimulation of the senses. Organismic theory stresses the importance of the system as a whole, besides its dynamical and essentially active aspects. The problem stated sounds quite modern and is illustrative of this crucial point: it is the biological way of thinking that grounded Gestalt theory (von Bertalanffy, 1949).

The early Gestalt concepts, however, are greatly intuitive and philosophical in essence. This is especially true in the case of Christian von Ehrenfels, who was the first to introduce the Gestalt concept as an overall quality of a content of consciousness, that transcends its component parts. This global concept has two major qualities (the Ehrenfels-criteria): the whole is more than the sum (Übersummenhaftigkeit) and the Gestalt can be transposed (Transponierbarkeit) (von Ehrenfels, 1890). The philosophical and psychological theories that were the outcome of these early conceptions, however, didn't always resist the challenges of empirical evidence. So Gestalt theory claims that in perception one can grasp 'immediately' a configuration that is already organized. The act of perception should recognize the configuration on the basis of a fundamental isomorphism between the 'structure of the object' and the 'psychophysiological structure' (Gestalt-like patterns of excitation in the brain) of the perceiver (Guillaume, 1937) . This premise however has been largely contested by postgestaltist authors (Piéron, 1955).

\subsection{Gestalt Concepts Revisited: an Operational Approach}

[59] 'Skilled' perception and 'schooled' listening are not concerned with isolated entities, but with their organization in structures and configurations. Structuring, however, is an active affair that leans heavily upon the higher functions of the brain (Reybrouck, 1989). The grouping phenomena of Gestalt psychology therefore can be formulated in terms of organizational principles, knowledge acquisition, categorization, schematization and abstraction, and this in a dynamic rather than a static way, since music is a dynamic system characterized by totality, organization and teleology (Stoianova, 1975). Music, in that sense, 
can be defined as a 'sound producing organis' (Coker, 1972; Reti, 1961; de Sélincourt, 1820), and the musical experience should be the outcome of an interaction between the listener and the musical organism. Music, thus defined, is an organic structure and music analysis has to be broadened from a structural description to a description in terms of processes (Rosenthal, 1989). To quote von Bertalanffy: "Organic structures are themselves expression of an ordered process; and they are only maintained in and by this process. Therefore, the primary order of organic processes must be sought in the processes themselves, not in the pre-established structures". (von Bertalanffy, 1967, p.73)

An operational description of this idea is possible by substituting a system for the organism. This system should be an 'open system' (von Bertalanffy, 1949, 1950), i.e. an organized whole that maintains a state of equilibrium under continuous import and export of material. What matters here is the conception of a dynamic morphology (Thom, 1972, 1980; Petitot, 1983, 1985) that stresses the importance of processes of growth. The structure of the organism therefore has to be conceived as a quasi-stationary state, that maintains itself for a while and then changes and disappears.

The listening process should mirror this development in a kind of morphodynamic analogy between the sonorous articulation and its image in the listener's mind. Schooled listening therefore not only involves the extraction of a morphological lexicon (Petitot, 1989) as a set of discrete entities, but also the construction of a relational network between them that allows a process-like description in terms of continuation and growth. The description of the combinations of the individual elements in a discrete-digital way, therefore, has to be supplemented with an analog description of the development of the whole, as a kind of envelopeplaced over the individual elements.

What matters here is an operational description of structures that group temporal courses in a broader organic chain. For this reason there is need for a conceptual apparatus that allows a gentle transition from a mechanical concept of form to an organic one, and that stresses the importance of structuring by the listener as well.

In this context we once again refer to the 'Gestalts' of von Ehrenfels as overall qualities that exist besides and above their components. The conceptualization concerning these qualities is [60] closely related to Husserl's phenomenological theory of time (Husserl, 1928) (both Husserl and Ehrenfels were inspired by Brentano) and especially his conception of the synthesizing function of time. The latter leans upon Brentano's idea that the grouping of a sequence of representations is not possible without being the simultaneous object of the knowing mind, that combines them in one singular act of consciousness. One has to make a distinction, therefore, between the unchangeable but divisible experience of real time and the essentially indivisible and continuous flow of the inner experience of time.

The importance of these earlier insights must be emphasized. Their intuitive formulation, however, is waiting for an operational approach, especially with respect to the definition of the 'time objects' as structural Gestalt-units and the transformations that can be applied to them.

One must further bear in mind that the 'perceived' structures are not necessarily isomorphic with the 'sounding' structures as such, because of the role of schemes and knowledge mediating between stimulus and response. The operational approach, therefore, not only applies to the structural description of music as an independent variable (the argument), but 
also to the perception by the listener as a dependent variable (the image) and the mediation between them (the function that maps the argument to its image).

What really matters here is not the structural description of the music as an artefact, but the whole set of transformations on these structures by the perceiving mind, from mere pattern recognition and heuristic procedures to more elaborate processes of information processing. And the formal approach par excellence for describing this, uses a formal language as suggested by semiotics (Morris, 1937/1975) and by neopositivism (Carnap, 1937/1971). In this approach the structures and patterns are considered as 'signs', that can be studied on a syntactical (the formal relations between the signs), a semantical (the meaning of the signs) and a pragmatical level (the effects of the signs on the user).

Semiotics, besides, has essentially an interdisciplinary base, but leans heavily upon symbolic logics. The categorization processes, e.g., that are at the core of schooled listening, can be formalized as predication processes, that apply to individual elements but also to complex configurations. In either case, the result is a set of propositions that are reducible to subjectpredicate relationships. A more promising approach, however, is the enlargement of these syllogistic categories to a description in terms of 'predicate and arguments, 'operator and operandum', or 'functor and arguments'. The profits of this approach are the possibilities of introducing algebraic methodologies in defining predicates and arguments as variables, that can be filled in without restrictions. From here, of course, one can skip gently to set theoretical, group theoretical and topological methodology. A Gestalt (structure), then, can be defined as a geometrical figure (a set of points), and the recognition of that Gestalt as performing an identification algorithm on transformations in geometrical sense (mere recognitions should be identical transformations, the other transformations should be classified as similarity transformations).

\section{Epistemological Implications or Gestalt Theory between Nature and Nurture}

[61] Gestalt perception of music is not merely a matter of musical structure, but is essentially dependent on structuring by the listener, since dealing with music is an active and constructive process. The construction, however, is not an arbitrary one, but can be directed as a result of learning and instruction and Gestalt principles may be helpful here.

\subsection{Structural Description and Functional Approach}

A starting point is the assumption that objects of knowledge and of perception have a system character. This is closely related to the holistic and biological way of thinking in stating that global structures resist destruction of some of their parts. Individual elements, in fact, are better perceived within a context (Palmer, 1977) than in isolation. This underlines the greater stability of global patterns that are stronger the more abstract they are. McNeill (1971) e.g. suggested an analogy between the characteristics of a sentence and a biological system. Every thought or every conscious perception should be correlated with a 'biolinguistic system' with a very short term of life. The application of these insights to other domains of perception is probable.

The system character of objects of knowledge, however, is not sufficient ground for its perception by the listener. The 'structural' description of the objects, therefore, has to be 
supplied with a 'functional approach'. Piaget (1968) has stressed the necessity of adding a subject to the structures as a centre of functioning. But the functional approach has been emphasized by other scholars as well. Jacob von Uexküll, e.g., developed his theory of the 'Umwelt' (world around us) as the combination of a perceptual and effector world, that are linked together by a functional cycle (von Uexküll, 1934/1957). This cycle operates by means of trigger mechanisms. Objects that are selected on account of their importance act as perceptual cue bearers, while other objects pass unnoticed. Objects with an operational meaning on the other hand act as functional cue bearers. Both are related in the sense that the functional qualities affect the perceptual ones. They transform the object of perception by giving it a 'functional tone'. Perception and effectuation are linked together, causing a closed loop. This is the 'Umwelt' of the animal, as the sum total of perceiving and performing.

'Umwelt'-research is highly informative and is directed primarily to the determination of the perceptual triggers of the existing stimuli. Every subject builds up relations with the external environment, selecting some of them to give them special meanings, and to construct his specific world or Umwelt.

\subsection{In Search of Universals of Knowing and Perception}

The functional approach provides an interesting extension of traditional perception theory, in linking sensorium and motorium. The objects of perception and knowledge receive an [62] operational meaning and can be influenced by processes of learning and selection (Edelman, 1989). Anyhow, the Umwelt of most animals is a rather closed universe that does not change spontaneously. It can be interesting therefore, to investigate the organization principles of perception and knowledge that are operating on a certain level of biological functioning (Edelman, Gall, \& Cowan, 1988; Wallin, 1991).

On the perceptual level there are the Gestalt laws, as formulated by Wertheimer $(1922,1958)$. The epistemological statute, however, of these laws is quite ambiguous, for there is some tension between what is innate (nature) and what is learned (nurture). Future research has to be directed to the physiological and psychobiological bases of perception, to uncover the innate equipment of the human species. Bruner e.g. (1957) postulated some 'perceptual primitives' or 'identities' that are not the outcome of a learning process. They concern innate categories as motion, causation, intention, identity, equivalence, time and space. And probably these epistemological primitives lean upon capacities that are still more primitive.

The problem that arises here is the question of the existence of 'universals of knowing and perception'. The answer is affirmative if one considers them as being the formal objects of the 'primary code' (Bystrina, 1983) This concerns all information without sign character (e.g. the rule-systems that are reducible to the genetic code, perception codes and intra-organismic codes). What matters here, once again, is the neurological and psychobiological substructure of perception. A domain of special interest in this connection is the study of 'ecological variables' in perception (Martindale \& Moore, 1989; Neisser, 1987) and musical universals in man and animal (Hulse \& Page, 1988).

Rule-systems that are the outcome of learning processes, on the other hand, are classified as 'secondary code'. They link production and reception of signs and sign-complexes, as elements of a broader context. What is concerned here are symbolic processes that are removed some distance from the sensory material. 


\subsection{Cognitive Abstraction: Categorization, Schematization and Prototypicality}

The first order of cognitive abstraction is symbolization, since symbols are not real things, but things that stand instead of them, and this in several kinds of relationships. One common point, however, is their lack of concrete and indiosyncratic qualities. The process of abstraction, therefore, is characterized by the extraction of invariants, so that differences in sensory modalities or modalities of perception evoke the same perceptual image. Thus one is classifying the input in categories on the basis of common features, that are stored in a more or less schematic way, so combining the methodologies of 'categorization' (Bruner, 1957; Rosch, 1973; Rosch, Gray, Johnson \& Boyes-Braem, 1976, Neisser, 1987; Edelman, 1989; [63] Gjerdingen, 1990), 'schematization' (Smolensky, 1988; Bharucha, 1987)], 'priming' (Martindale \& Moore, 1989) and perception theory.

Categorization, however, is not a passive registration of ready-made stimuli, but a constructive process, that integrates sensation, perception and cognition. Listening, therefore, is a matter of information processing, that integrates several levels of processing in one global process [(Camilleri, 1989; Neisser, 1967; Seifert, 1993). At the lowest level there are systems for recognizing patterns whose information is contained in the external world. Assigning these pattern to music, however, cannot be done on a priori-grounds, for the delimitation of musical patterns is greatly influenced by the selection processes and the decoding mechanisms of the listener. The feature theory or ecological theory of perception, e.g., [Gibson \& Gibson, 1957) states that the perceiver learns to discriminate a number of distinctive features. At the core of this theory is an increase in differentiation and discrimination as the result of a perceptual learning process. Schema-theory, on the contrary, starts from the assumption that a 'schema' or 'model' is built up in the listener's mind. Both hypotheses are not opposed but are complementary in the sense that the construction of a standard as a reference leans upon learning to discriminate more and more features to integrate them in a schema that acts as a prototype for discrimination between categories and for classification of patterns in well-defined categories.

Perception, thus, is dependent on the search requirements of the perceiver. These can be minimal in an attempt to structure the stimuli in the most economical way, but can be very significant as well. Yet, some configurations impose their structures in a more compelling way. The organizing principles at work here are almost unequivocally referring to the imposition of stability on external stimuli, as has been stated in the 'law of pregnancy' of Koffka (1935) and the 'law of good form' of Wertheimer (1922). They claim that good form is the most simple, the most regular and the most symmetrical of the possible forms in the actual circumstances.

\subsection{Perception as an Active and Transactional Process}

Perception, as an active and transactional process between perceiver and environment, is an organisation of the perceptual input in search of meaning. The central question, here, is the role of learning and instruction, since the expert sees patterns of organized information where the novice sees only unrelated details (Davidson \& Welsh, 1988). At the core of this problem is the everlasting debate of nativism versus empiricism: is perception the outcome of construction as a result of interaction between sensory and motor behavior (nurture) or are there innate receptor mechanisms that function in an autonomous way (nature) (Tighe \& 
Dowling, 1993; Hargreaves, 1986). The traditional dichotomy, however, has been weakened since perception and learning theories are gradually coming together, redefining the nativistic [64] conception as a kind of information-extraction and the empiricistic one as an important moment in perception theory (Hargreaves, 1986).

In connection with this, perception can be defined as a kind of learning with former experiences, this being as important as actual learning in the perceiving act. Perception, thus, cannot ignore processes of acculturation, enculturation, and conditioning. And this emphasizes the importance of the reader over the text, as has been stressed by reception aesthetics (Iser, 1970; Jauss, 1975, 1977). Much will depend, however, on the construction of an internal model of the external environment that can function as a trigger mechanism for Gestalt-like recognition of stimulus configurations (Sloboda, 1985). For these schemas are directing our attention, in establishing correspondences between type-figures of the external stimuli and those that are stored in memory. And this, in fact, is a simple interpretation of schema theory: new structures are matched against existing ones.

\section{Applying Gestalt Concepts on Music Analysis}

One has to be cautious in applying Gestalt concepts on music analysis. Gestalt-theoretical concepts and their experimental research focused primarily on visual experiences. The translation of insights from the visual to the auditive domain is highly speculative, since music, as a temporal art, is essentially discursive. In contrast with a geometrical figure, that is described as a whole when looking at it, a musical figure needs a successive presentation. The grasping of its meaning, then, is 'polythetic' in that it can be grasped only by hearing the music as it unfolds step by step (Wright, 1995). This hampers the holding of a musical Gestalt as an immediate and directly experienced whole. Music, however, can be grasped in a 'monothetic' way, if the discursive processes are coded as discrete things as in the case of conceptualization (McAdams, 1985). The monothetic grasping of temporal Gestalts can then be defined as a combination of actual and virtual impressions of sounds. The epistemological statute of these Gestalts, however, has still to be clarified.

A second problem is the complexity of the musical texture, that is mostly composed of multiple layers. In order that Gestalt perception can be directed to one of these layers (figure/ground) or to the sum of these, there is, in both cases, some focusing and direction of attention by the listener (Sloboda, 1985; Dowling \& Harwood, 1986). Auditive perception, therefore, is a result of heuristic processes that analyse the auditive field in component parts (Bregman, 1978, 1981, 1990). The extraction of meaningful constituents out of a complex acoustic input is not an arbitrary process, but is constrained by principles of grouping and dividing, as described by Gestalt psychology.

Dividing, however, is an analytical process, and there is a danger of reducing the biological way of thinking to a structural description. The problem has been formulated by Souris (1976) who stated that traditional music theory dismisses the internal reactions of the elements. Real [65] music, therefore, only exists when it is sounding, with every sound being responsible for the overall texture. There is much sense, then, in speaking of auditory 'events' or 'scenes', rather than of isolated structures (Bregman, 1990, Krumhans1, 1992, McAdams, 1989).

A third problem is the need for simultaneous and successive decoding of the music. For musical structure is composed of simultaneous) and successive Gestalts (Volkelt's 
'Simultangestalten' and 'Verlaufsgestalten' (1959). The grasping of successive Gestalts leans upon temporal decoding mechanisms, in an attempt to segregate the sonorous articulation in temporal Gestalt-units, as distinct spans of time that are both internally cohesive and externally segregated from comparable time-spans immediately preceding and following them (Tenney \& Polansky, 1980; Jones, 1982, 1976; Jones \& Boltz, 1989; Jones \& Holleran, 1992; McAdams, 1989). The operational approach of simultaneous decoding, on the other hand, is more difficult, because simultaneity can be actual or virtual. Actual simultaneity leans upon real sonorous articulation, and can be the object of empirical research. Virtual simultaneity leans upon memory and imagination, and can't be studied in a direct way.

There is, finally, the problem of mental involvement with the music. Two possibilities of tapping this moment-to-moment history are open here: the listening process mirrors the actual sonorous articulation in inexorable time or the process involves mental operations that are independent of inexorable time. This distinction is important, because it places constraints on using one Gestalt concept for describing both groupings in real time (real sonorous groupings) and in the imagination. The latter are dependent on the synthetic function of consciousness, substituting virtual images for actual perception. This can be done in an 'a priori' (synthesis by anticipation) or an 'a posteriori'-way (synthesis for memory). The solution, however, of this problem is not easy and is waiting for further semiotic research (Reybrouck, 1995).

\section{Conclusion}

In this paper we presented an overview of some Gestalt concepts as applied to music. We have proposed an enlargement of the traditional concepts focusing primarily on an operational and interdisciplinary approach. Nevertheless we are deeply impressed by the modernity of some of the early insights as e.g. the organismic and the functional approach. These have to be placed, however, in the framework of modern methodology with special emphasis on the neuropsychological and psychobiological approach. Besides, there is the definition of music as a temporal art, as music is essentially a function of time. Listening, therefore, is a discursive process, that leans upon memory and imagination. Another point finally, is the role of mediation by the listener's mind, because there is no linear relation between the musical structure and the listening behaviour. Music analysis, therefore, has to be broadened from a structural to a functional approach, stressing the importance of learning processes and modulating factors of attention and motivation.

\section{References}

Bharucha, J. (1987). Music Cognition and Perceptual Facilitation: A Connectionist Framework. Music Perception, 5 (1): 1-30.

Bregman, A. (1978). The Formation of Auditory Streams. In J.Requin (Ed.). Attention and Performance. VII. Hillsdale - New Jersey: Erlbaum.

Bregman, A. (1981). Asking the "what for" question in auditory perception. In M.Kubovy \& J.Pomerantz (Eds.). Perceptual Organization. Hillsdale: Erlbaum.

Bregman, A. (1990). Auditory Scene Analysis.: the Perceptual Organization of Sound,. Cambridge, MA.: MIT.

Bruner, J. (1957). On Perceptual Readiness. Psychological Review, 64: 123-152.

Bystrina, I. (1983). Kodes und Kodewandel. Zeitschrift für Semiotik, 5: 1-22.

Camilleri, L. (1989). A Modular Approach to Music Cognition. Interface, 18: 33-44. 
Carnap, R. (1937). The Logical Syntax of Language. London: Routledge \& Kegan Paul.

Coker, W. (1972). Music and Meaning. A Theoretical Introduction to Musical Aesthetics. New York - London: Free Press/ Collier - Macmillan.

Davidson, L. \& Welsh (1988). From collections to structure: the developmental path of tonal thinking. In J.Sloboda (Ed.). Generative Processes in Music. The Psychology of Performance. Improvization and Composition. Oxford: Clarendon Press.

Dowling, W. and Harwood, D. (1986). Music Cognition. Orlando: Academic Press.

de Sélincourt, B. (1820). Music and Duration. Music and Letters, I, 4: 286-293.

Edelman, G. (1989). Neural Darwinism. The Theory of Neuronal Group Selection. New York: Oxford University Press.

Edelman, G., Gal, W. \& Cowan, W., (Eds.) (1988). Auditory Function: Neurobiological Bases of Hearing. New York: John Wiley \& Sons.

Gjerdingen, R. (1990). Categorization of Musical Patterns by Self-Organizing Neuronlike Networks. Music Perception, 7, 4: 339-370.

Gibson, E. \& Gibson, J. (1957). Principles of Perceptual Learning and Development. Englewood Cliffs, New York: Prentice Hall.

Guillaume, P. (1937). La Psychologie de la Forme. Paris: Flammarion.

Hargreaves, D. (1986). The Developmental Psychology of Music. Cambridge: Cambridge University Press.

Hofstadter, D. (1986). Metamagical Themas: Questing for the Essence of Mind and Pattern. Harmondsworth: Penguin Books.

Hulse, S. \& Page, S. (1988). Toward a Comparative Psychology of Music Perception. Music Perception, 5, 4, 427-452.

Husserl, E. (1928). Vorlesungen zur Phänomenologie des inneren Zeitbewusstseins (Ed M.Heidegger), Jb. für Philosophie und Phänomenologische Forschung, 9, 367-489.

Iser, W. (1970). Die Appelstruktur der Texte. Unbestimmtheit als Wirkungsbedingung literarischen Prosa. Konstanze: Universitätsverlag.

Jauss, H. (1975). Der Leser als Instanz einer neuen Geschichte der Literatur. Poetica, 7: 325344.

Jauss, H. (1977). Aesthetische Erfahrung und literarische Hermeneutik. Bd.I, Versuche im Feld der ästhetischen Erfahrung. München: Fink.

Jones, M.R. (1982). Music as a stimulus for psychological motion: Part II. An expectancy model. Psychomusicology, 2: 1-13.

Jones, M.R. (1976). Time, our Lost Dimension: Toward a New Theory of Perception, Attention, and Memory. Psychological Review, 83, 5: 323-355.

Jones, M.R. \& Bolz, M. (1989). Dynamic attending and responding to time. Psychological Review, 96: 459-491.

Jones, M.R. \& Holleran, S., (Eds.) (1992). Cognitive Bases of Musical Communication. Washington: American Psychological Association.

Koffka, K (1935). Principles of Gestalt Psychology. New York: Harcourt.

Köhler, W. (1929). Gestaltpyschology. New York: Liveright.

Krumhansl, C. (1992). Internal Representations for Music Perception and Performance. In M.R.Jones and S.Holleran (Eds.). Cognitive Bases of Musical Communication. Washington: APA.

Martindale, C. and Moore, K. (1988). Priming, prototypicality, and preference. Journal of Experimental Psychology: Human Perception and Performance, 14: 661-670.

Martindale, C. \& Moore, K. (1989). Relationship of Musical Preference to Collative, Ecological, and Psychophysical Variables. Music Perception, 6 (4): 431-446. 
McAdams, S. (1989). Contraintes psychologiques sur les dimensions porteuses de forme en musique. In S.McAdams \& I.Deliège (eds.). La musique et les sciences cognitives. Bruxelles: Mardaga.

McNeill, D. (1971). Sentences as Biological Systems. In P.Weiss (Ed.). Hierarchically Organized Systems in Theory and Practice (pp. 59-67). New York: Hafner.

Morris, C. (1975/1935). Foundations of the Theory of Signs. Vol.1, nr.2, Chicago \& London, University of Chicago Press.

Neisser, U. (1967). Cognitive Psychology. New York: Appleton - Century Crofts.

Neisser, U. (1987). Concepts and conceptual development: Ecological and intellectual factors in categorization. New York: Cambridge University Press.

Palmer, S. (1977). Hierarchical Structure in Perceptual Representation. Cognitive Psychology, 9:441-474.

Petitot, J. (1983). Paradigme catastrophique et perception catégorielle. Recherches sémiotiques (RS/SI), 3: 207-245.

Petitot, J. (1985). Les catastrophes de la Parole. De Roman Jakobson à René Thom. Paris: maline.

Petitot, J. (1989). Perception, cognition et objectivité morphologique. In S.McAdams and I.Deliège (Eds.). La musique et les sciences cognitives. Bruxelles: Mardaga.

Piaget, J. (1968). Le structuralisme. Paris: P.U.F.

Piéron, H. (1955). Rapport au Symposium “La Perception”. Louvain. Paris: P.U.F.

Reti, R. (1961). The Thematic Process in Music. London: Faber \& Faber.

Reybrouck, M. (1989). Music and the Higher Functions of the Brain. Interface, 18, 1-2: 7388.

Reybrouck, M. (1995). Spanning en Ontspanning in de Muziek. Een semiotische benadering van de omgang met muziek. (Tension and Relaxation in Music. A Semiotic Approach of Dealing with Music. Unpublished doctoral dissertation. Louvain.

Rosch, E. (1973). On the internal structure of perceptual and semantic categories. In T.Moore, (Ed.). Cognitive development and the acquisition of language, New York: Academic Press.

Rosch, E., Gray, W., Johnson, D. \& Boyes-Braem (1976). Basic objects in natural categories. Cognitive Psychology, 8: 382-439.

Rosenthal, D. (1989). A Model of the Process of Listening to Simple Rhythms. Music Perception, 6, 3: 315-328.

Schutz, A. (1970). Fragments on the Phenomenology of Music (Ed. F.Kersten). Music and Man, Vol.2, § 14.

Seifert, U. (1993). Systematische Musiktheorie und Kognitionswissenschaft. Zur Grundlegung der kognitiven Musikwissenschaft. Bonn: Verlag für systematische Musikwissenschaft.

Sloboda, J. (1985). The Musical Mind. The Cognitive Psychology of Music. London: Clarendon Press.

Smolensky, P. (1988). On the proper treatment of connectionism. Behavioral and Brain Sciences, 11: 1-74.

Souris, A. (1976). Conditions de la musique et autres écrits. Bruxelles - Paris: Editions de l'Université de Bruxelles.

Stoianova, I. L'énoncé musical. Musique en jeu, 19: 23-57.

Tenney, J. \& Polansky, L. (1980). Temporal Gestalt Perception in Music. Journal of Music Theory, 24 (2): 205-241.

Thom, R. (1972). Stabilité structurelle et Morphogenèse. New York: Benjamin.

Thom, R. (1980). Modèles mathématiques de la Morphogenèse. Paris: Bourgois.

Tighe, J. and Dowling, W. (1993). Psychology and Music. The Understanding of Melody and Rhythm. New Jerse: Lawrence Erlbaum Associates. 
Volkelt, H. (1959). Simultangestalten, Verlaufsgestalten und Einfülung. Zeitschrift für experimentelle und angewandte Psychologie, 6: 357-371.

Von Bertalanffy, L (1949). Das biologische Weltbild. Bern: Francke Verlag.

Von Bertalanffy, L. (1950). The Theory of Open System in Physics and Biologia. Science, 111.

Von Bertalanffy, L (1967). Robots, Men and Minds. Psychology in the Modern World. New York: Braziller.

Von Ehrenfels, C. (1890). Über Gestaltqualitäten. Vierteljahrschrift für Wissenschaft. Phil., XIV.

Von Uexküll, J. (1956/1934). A Stroll Through the Worlds of Animals and Men. A Picture Book of Invisible Worlds. In C.Schiller (ed.). Instinctive Behavior. The Development of a Modern Concept (pp. 5-80). New York: International Universities Press.

Wallin, N. (1991). Biomusicology: Neuropsychological and Evolutionary Perspectives on the Origins und Purposes of Music. New York: Pendragon Press.

Wertheimer, M. (1922). Untersuchungen über die Lehre von der Gestalt. Psychologische Forschung, 1, 47-58.

Wertheimer, M. (1958). Principles of Perceptual Organization. in: D.C.Beardslee and M.Wertheimer, (Eds.). Readings in perception. Princeton, NJ: Van Nostrand.

Wright, D. (1975). Musical Meaning and its Social Determinants. Sociology, 9, 419-435. 